\title{
Transformer Fault Detection by Frequency Response Analysis
}

\author{
Ilampoornan.M.K ${ }^{1}$, Vikash.M ${ }^{2}$ \\ ${ }^{I}$ (Professor, EEE Department, Loyola institute of technology/ Anna University, Tamil nadu, India) \\ ${ }^{2}$ (M.E Student, EEE Department, Loyola institute of technology/ Anna University, Tamil nadu, India)
}

\begin{abstract}
The Power transformers are one of the most vital as well as expensive equipment in an electric power system. Therefore, it is the responsibility of utilities to decrease the transformer lifecycle costs and to increase the usable service time. The damage may cause a change in the physical condition of transformer which would be reflected in the electrical parameters- resistance, inductance and capacitance. The insulation performance is influenced by thermal, electrical and mechanical stresses. The displacement of windings can occur during transportation of transformers or during a short circuit near the transformer in the power system. The Frequency Response Analysis (FRA) can detect the type of fault and the exact location of fault. The result obtained for the various fault condition is compared with the reference set and the conclusion are drawn.
\end{abstract}

Keywords - Fra,Ehv,Sfra,Lvi,Hv.

\section{INTRODUCTION}

This work proposes to detect short circuit faults between two turns in a winding of a transformer and mechanical displacement. Power transformers are the most expensive single elements of EHV transmission systems. Therefore, it is the prime duty of utilities to decrease the transformer life cycle costs and to increase the usable service life. One possibility is to extend the monitoring and diagnosis of power transformers to all possible types of faults. Special monitoring devices for the detection of different types of faults are in use. Transformers are designed to withstand the effects of limited duration short circuit at their terminals. This ability can be affected by thermal and transient mechanical stresses, which occur during operation. Especially, power transformers having a winding displacement caused by a mechanical stress due to a short circuit which is critical. Generally such pre-damaged power transformers show a serious fault when a next short circuit event occurs. To ensure a sufficient ability to withstand short circuit, the operating personal should identify such predamaged power transformers. In the standard, the reactance measurement is the basic detection method to demonstrate the integrity of the windings.

\section{SHORT CIRCUIT FAULT IN WINDINGS}

System short circuit may occur across any two lines or if the neutral point is earthed between any one lines. The effect of system short circuit will produce over currents, magnitude of which are dependent on the system MVA, feeding the fault or the voltage, which has been short circuited and on the impedance of the circuit up to the fault. Short circuit may cause winding movement and shorted turns. Short circuits near transformers usually cause currents of high amplitudes. This leads to extreme mechanical stress of core and coil assembly. The mechanical forces do not always cause a failure. Sometimes there is only some significant damage, which are not recognized and further service is not possible.

\section{SHORT CIRCUIT FORCES}

The insulation performance is influenced by thermal, dielectric and mechanical aspects. Electrical and thermal failure mechanisms and the forces resulting from the short circuits can damage the transformers. The short circuit withstand capability of a power transformer is defined as the ability to withstand the full asymmetrical short circuit currents without impairing its suitability for normal service conditions. Steady increase in unit ratings of transformers and simultaneous growth of short circuit levels of networks have made the short circuit withstand capability of the transformer one of the most important aspect of its design. The short circuit may lead to symmetrical short circuit currents of the order of 6-7 times the rated current and peak asymmetrical current as high as 15-18 times the rated current. The basic formula for force acting on a current carrying conductor in a magnetic field at any instant is given by:

F=BIL Newton

Where,

B-Flux density in Tesla

I-Current in Amperes

L-Length of the conductor in Meters

This means that resulting forces shall be tremendously high since they will increase in square of the current. These forces shall be exerted directly on all current carrying parts of the transformer in a magnetic field. 
Transformer Fault Detection by Frequency Response Analysis

Short circuit forces are of pulsating nature since short circuit current and flux are sinusoidal. Therefore, time variable stresses are applied to the affected structures. These forces are very high during the first asymmetrical peak and come down to the symmetrical rms value. The forces generated during short-circuit are transferred to all parts mechanically coupled to winding assembly. The effects of these forces are radial force due to leakage field distribution during short-circuit and axial forces will be generated due to mechanical stress of the end rings.

\section{DETECTION TECHNIQUE}

If the transformer has been switched off by protective equipment, there is a need to determine whether the transformer can be safely re-energized. Visual inspections require dismantling of the transformer, removing of the transformer oil and are time consuming. Hence effective detection techniques are required. The most commonly used techniques are:

1. Leakage reactance measurement

2. Low voltage impulse

3. Frequency response analysis

\section{HISTORICAL DEVELOPMENT IN FAULT DETECTION TECHNIQUE}

Before 1980, LVI tests were performed on transformers in order to obtain the information considering the transformer condition. In this method, a very steep impulse was applied to one of the HV terminals and the response signal across a $50 \Omega$ resistor was recorded. For mechanical faults, neither method (LVI or FRA) is used. For electrical faults, the swept frequency method gives better results because it has a finer resolution at low frequencies. The LVI method is subjected to several disadvantages and hence FRA is widely used to detect winding deformation.

\section{DISADVANTSGES OF LVI METHOD}

1. It is subjected to interference effects.

2. It requires extensive calibration procedures.

3. It also requires a specially constructed and finely trimmed instrumentation system to obtain repeatable results.

4. The amount of power injected into the test object is different at different frequencies. This leads to differences in precision across the frequency range.

5. It is difficult to filter out broad band noise.

Swept frequency response analysis (SFRA) method removes many of these difficulties while increasing the sensitivity of detecting winding deformation.

\section{FREQUENCY RESPONSE ANALYSIS}

Frequency response analysis (FRA) consists of measuring the impedance of a transformer winding over a wide range of frequencies and comparing the results with a reference set. This FRA technique is gradually being introduced in the field of power transformer testing and diagnosing. Differences may indicate damage to the transformer, which can be investigated further using other techniques or by an internal examination.

\section{DIAGNOSING FAULTS}

Faults, such as short-circuited turns, change the magnetizing characteristics of the transformer and, hence, the low-frequency response. Circulating currents loops, if they are sufficiently large, redirect leakage flux into the core and also change the low-frequency response. An ungrounded core changes the shunt capacitance of the winding closest to the core and also the low-frequency response. The medium-frequency response is sensitive to faults that cause a change in the properties of the whole winding. A significant increase in the medium-frequency resonances normally indicates axial movement of a winding. A significant decrease normally indicates radial movement of the inner winding. Slight differences are often accepted as being a result of "windings settling into place."

The high-frequency response is sensitive to faults that cause changes in the properties of parts of the winding. Localized winding damage causes seemingly random changes in the high-frequency response, often leading to the creation of new resonant frequencies. The high-frequency response may also be affected by the tank or cable grounding. Poor tank grounding is easy to spot, as it affects all windings, whereas damage is usually confined to one winding or at worst one phase. Poor cable grounds are more difficult to detect, as they may cause changes to just one winding, but are unlikely to lead to the creation of new resonant frequencies. 
Transformer Fault Detection by Frequency Response Analysis

\section{MEASUREMENT OF WINDING DEFORMATION IN POWER TRANSFORMERS USING FRA METHOD}

When a transformer is subjected to high through fault currents, the mechanical structure and windings are subjected to large mechanical stresses. These stresses may cause serious deformation of winding and precipitate a transformer failure. Winding deformation is difficult to determine by conventional measurements of ratio impedance and inductance and capacitance of the winding structure. These changes can be detected externally by FRA method.

\section{MODELLING OF TRANSFOMER WINDING}

A simplified equivalent circuit for one outside phase of the winding of the 8 MVA, 110/22 kV, wyedelta power transformer, using cascade $\pi$ section is modeled for eight sections which equals to the number of winding disc in the transformer refer fig-(1). The model consists of eight sections. The equivalent circuit is useful in modeling and is sensitive to winding changes. Conversely, a change in response could be related to a calculated amount of winding deformation. In a winding there exists capacitance between the adjacent turns within a disc or layer, capacitance between the adjacent discs or layers, capacitance to ground and to other windings. Similarly there exists self and mutual inductances as pertaining to the individual turns, the disc/sections, one part the winding to another or one whole winding to another. Although both capacitance and inductance are of distributed nature, for practical computation purposes these have to be lumped in varying degrees according to the desired accuracy. Also, the effect of the winding resistance is not significant and can therefore be neglected.

\section{SIMULATION OF FAULTS}

The Frequency response analysis can detect many type of faults includes short circuit fault, interturn fault, failure of transformer oil and mechanical displacement. These faults are thus simulated and the frequency response is obtained.

\section{Short circuit fault}

Short circuit faults are simulated by including a resistor between the nodes at which the fault occurrence is to be analyzed refer fig-(2) and table-1.The circuit may be studied for various resistor values like $100 \Omega, 1 \mathrm{k} \Omega$ and $10 \mathrm{k} \Omega$. It can be seen from the analysis that the behavior of the circuit changes from that resembling a short $(\mathrm{R}=100 \Omega)$ to that resembling an unfaulted case $(\mathrm{R}=10 \mathrm{k} \Omega)$. The intermediate value $(\mathrm{R}=1$ $\mathrm{k} \Omega$ ) shows the transition. For the analysis purpose, consider $\mathrm{R}=100 \Omega$, which resembles a short.

\section{Interturn fault}

The inter-turn faults are better expressed by variation in series capacitance. The occurrence of short between the turns is indicated by including a resistor $(\mathrm{R}=100 \Omega)$ across the series capacitance of winding. Similarly, the fault across each winding can be simulated and frequency response is obtained. The frequency response analysis for short circuit fault across adjacent discs of the winding refer fig-(3) and table-2.

\section{Failure of transformer oil}

The failure of insulation or dielectric is simulated by adding a resistor across the ground capacitance. The ground capacitance denotes the distance between the core and the winding, which indicates that a fault has occurred between the winding and the core. The resistor $(\mathrm{R}=100 \Omega)$ is included across each ground capacitor and the frequency response is obtained refer fig-(4) and table- 3 .

\section{Axial displacement of winding}

The axial displacement of the winding is referred as vertical displacement. The vertical displacement is simulated by causing a change in the coupling value between two windings. Hence the coupling value is reduced by 0.1 and 0.2 for each section and the frequency response is obtained refer fig-(5) and table- 4 .

\section{Radial displacement}

The displacement of winding from the core is referred as the horizontal displacement. Horizontal displacement causes a change in the ground capacitance value. Hence the ground capacitance value is increased for each section and the frequency response is obtained refer fig-(6) and table5. 
XII. FIGURES AND TABLES

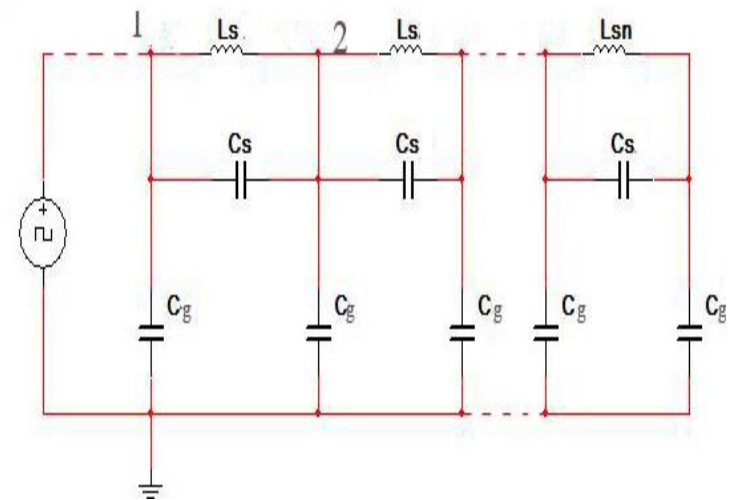

Fig (1): Equivalent circuit of 8 MVA transformer winding

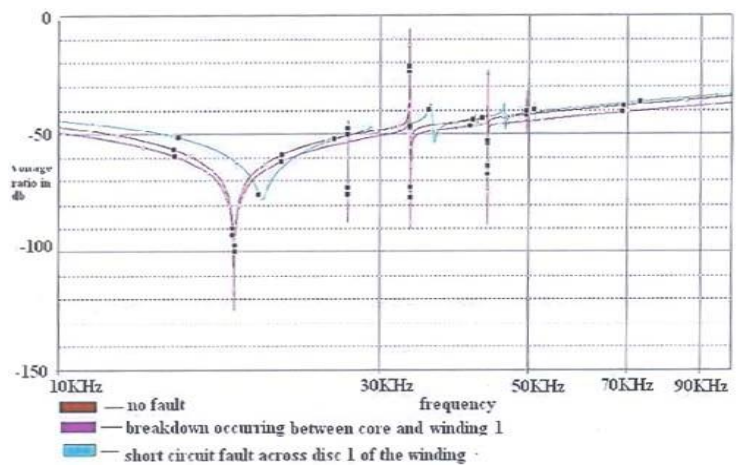

Fig (2): Comparison of no fault with short circuit fault across disc 1 of the winding and breakdown occurring between core and winding at resonant frequencies.

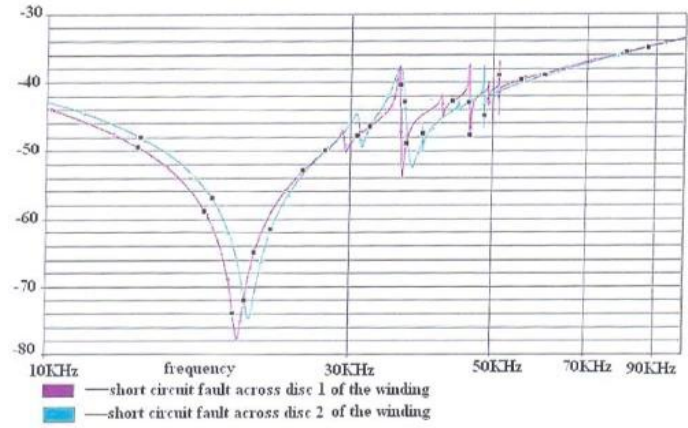

Fig (3): Comparison of short circuit fault across disc 1 and disc 2 of the winding.

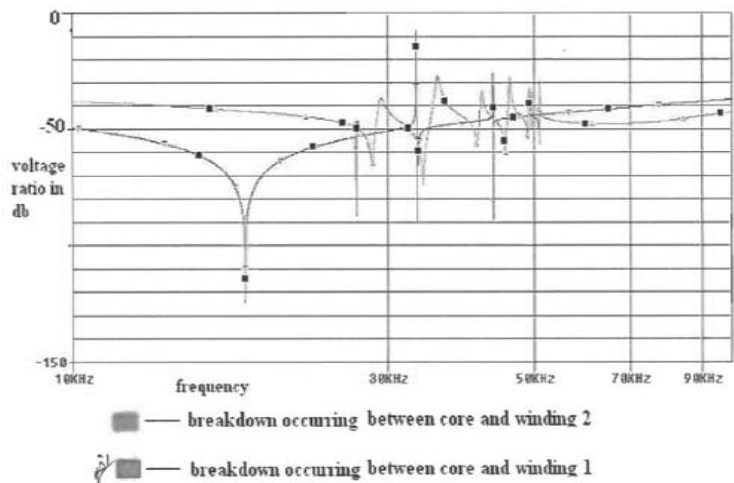

Fig (4): Comparison of breakdown occurring between core and winding 1 with breakdown occurring between core and winding 2 at resonant frequencies. 


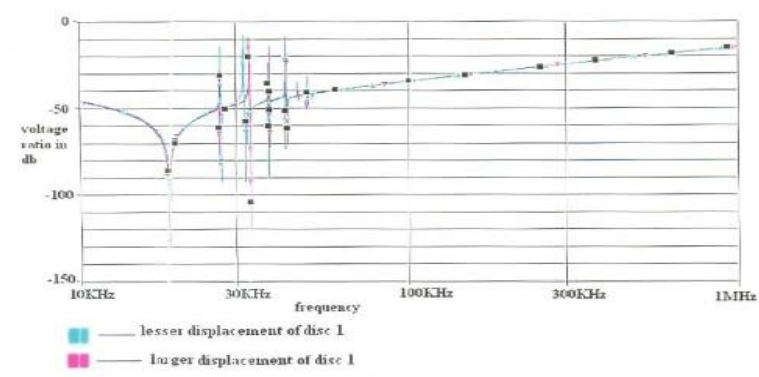

Fig (5). Comparison of axial displacement of disc 1.

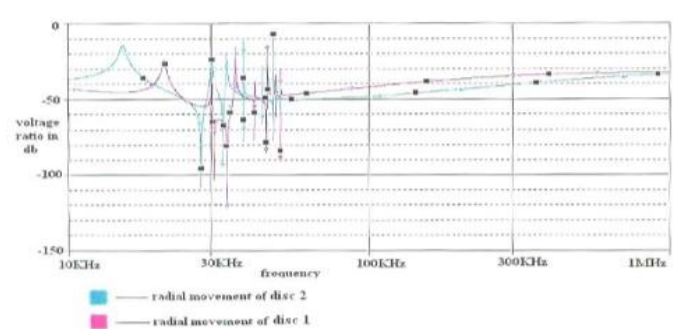

Fig (6). Comparison of radial displacements of disc 1 and disc 2.

\begin{tabular}{|l|l|l|l|}
\hline Poles & $\begin{array}{l}\text { Resonant } \\
\text { Frequencies of } \\
\text { NoFault } \\
\text { Responsein } \\
\text { kHz }\end{array}$ & $\begin{array}{l}\text { ResonantFrequenciesof } \\
\text { ShortCircuitFaultAcross } \\
\text { Disc1ofTheWinding in kHz }\end{array}$ & $\begin{array}{l}\text { Resonant Frequencies } \\
\text { ofBreakdown } \\
\text { OccurringBetween Core } \\
\text { and Winding 1 in kHz }\end{array}$ \\
\hline 1 & 26.903 & 29.141 & 26.884 \\
\hline 2 & 33.167 & 35.752 & 33.197 \\
\hline 3 & 43.391 & 41.476 & 43.311 \\
\hline 4 & 49.636 & 45.825 & 49.556 \\
\hline 5 & - & 49.102 & - \\
\hline 6 & - & 51.015 & - \\
\hline
\end{tabular}

Table 1: Comparison of no fault with short circuit fault across disc 1 of the winding and breakdown occurring between core and winding at resonant frequencies.

\begin{tabular}{|l|l|l|}
\hline Poles & $\begin{array}{l}\text { Resonant Frequencies of Short Circuit } \\
\text { Fault Across Disc } \mathbf{1} \text { of the Winding in } \mathbf{k H z}\end{array}$ & $\begin{array}{l}\text { Resonant Frequencies of Short Circuit } \\
\text { Fault Across Disc 2 of the Winding in } \mathbf{k H z}\end{array}$ \\
\hline 1 & 29.141 & 30.669 \\
\hline 2 & 35.752 & 35.760 \\
\hline 3 & 41.476 & 38.905 \\
\hline 4 & 45.825 & 44.218 \\
\hline 5 & 49.102 & 48.350 \\
\hline 6 & 51.015 & 50.886 \\
\hline
\end{tabular}

Table 2: Comparison of short circuit fault across disc 1 and disc 2 of the winding.

\begin{tabular}{|l|l|l|}
\hline Poles & $\begin{array}{l}\text { Resonant Frequencies of Breakdown } \\
\text { Occurring Between Core and Winding } \mathbf{1} \text { in } \\
\mathbf{k H z}\end{array}$ & $\begin{array}{l}\text { Resonant Frequencies of Breakdown } \\
\text { Occurring Between Core and Winding 2 in } \\
\mathbf{k H z}\end{array}$ \\
\hline 1 & 26.884 & 29.289 \\
\hline 2 & 33.197 & 35.777 \\
\hline 3 & 43.311 & 41.754 \\
\hline 4 & 49.556 & 45.952 \\
\hline 5 & - & 49.181 \\
\hline 6 & - & 51.062 \\
\hline
\end{tabular}

Table 3. Comparison of breakdown occurring between core and winding 1 with breakdown occurring between core and winding 2 at resonant frequencies 


\begin{tabular}{|l|l|}
\hline \multicolumn{2}{|c|}{ Axial Displacement in Disc 1 } \\
\hline & $\begin{array}{l}\text { FREQUENCY OF } \\
\text { FIRST POLE IN kHz }\end{array}$ \\
\hline $\begin{array}{l}\text { LARGER } \\
\text { DISPLACEMENT }\end{array}$ & 26.588 \\
\hline $\begin{array}{l}\text { LESSER } \\
\text { DISPLACEMENT }\end{array}$ & 26.509 \\
\hline $\begin{array}{l}\text { DIFFERENCE } \\
\text { BETWEEN THE } \\
\text { FREQUENCIES }\end{array}$ & 79 \\
\hline
\end{tabular}

Table 4. Comparison of axial displacement of disc 1

\begin{tabular}{|l|l|}
\hline $\begin{array}{l}\text { Radial } \\
\text { Displacement in }\end{array}$ & $\begin{array}{l}\text { Frequency of Peak } \\
\text { Occurrence in } \mathbf{~ k H z}\end{array}$ \\
\hline DISC 1 & 20.898 \\
\hline DISC 2 & 14.792 \\
\hline
\end{tabular}

Table 5. Comparison of radial displacements of disc 1 and disc 2 .

\section{CONCLUSION}

Every transformer winding has a unique signature that is sensitive to changes in the parameters of the winding, namely resistance, inductance, and capacitance. Frequency spectrum of a transformer is very sensitive to any deformation or displacement of the winding. Frequency response analysis is a very effective tool for diagnosing transformer condition. It is particularly useful in detecting any fault that is due to mechanical damage to the winding. The technique is also very reliable for detecting any short circuit to the winding. Results from a measurement can be analyzed through several techniques via graphical presentation. However, reference is needed for better interpretation. The reference can either be from historical data of the same transformer or from sister transformers. In many cases, historical data for transformers already in operation is difficult to get owing to shutdown requirement. Sister transformers are used in those cases as the reference measurement. The interpretation of the results is meanwhile a great help in determining further action to be taken especially for suspected transformers. FRA can be a very effective tool for condition monitoring. It can avoid catastrophic failure in transformers and also help maintenance engineer to estimate time and cost for repairing the transformer after the fault before undertaking maintenance.

\section{References}

[1] Ryder (2003) 'Diagnosing transformer faults using frequency response analysis'- IEEE Electrical Insulation Magazine, pp 16-22.

[2] P.T.M. Vaessen, E. Hanique (January 1992) ‘A New Frequency Response Analysis Method for Power Transformers'- Transactions on power delivery, vol.7, No.1, PP 384-389.

[3] K. Feser, J. Christian, C. Neumann, U. Sundermann, T. Leibfried, A. Kachler, M. Loppacher- 'The Transfer Function Method for Detection of Winding Displacements on Power Transformers after Transport, Short Circuit or 30 Years'. 